\title{
Introduction of a Novel Paper Triage Tag
}

\author{
Hyo-young Kang, BSc; Myeong-il Cha, MD
}

$\mathrm{A}$ $\mathrm{t}$ a disaster site where multiple casualties are awaiting medical care, medical first responders must start their activities with triage. ${ }^{1}$ Currently, there are several triage algorithms for sorting patients rapidly and accurately, ${ }^{2}$ with 4 colors commonly used worldwide: Red (Immediate), Yellow (Delayed), Green (Minimal), and Black (Deceased).

Triage tags usually have tear-off side-by-side tabs, representing patient's severity (Figure 1A). However, this type of tearing makes it very difficult to perform re-triage; it allows only for representation of worsening status. Sometimes, all intact tabs can cause confusion among care providers: Does this mean minimally injured patient? Or not yet triaged?

One day, we noticed that a square-shaped sheet of paper has 4 edges, just like the 4 colors used in a triage tag! Hence, we wondered whether it would be a good idea to tear off an edge of a sheet of paper to show the triage result (Figure 1B).

As shown in Figure 1B, we designed a colored paper located in the rear, and the edges of the black-andwhite front paper could be easily cut. A full white paper means "Not yet triaged," and any color seen means "Already triaged." If you want to make changes in the triage result, as shown in Figure 2, simply tear off an edge of the rear page and perform triage again. The top page, which is usually kept by the field medical responders, can provide information about the severity of injury without any color; the shape of the cutting edges indicate severity, although it can become more complicated when you perform triage more than twice. Gathering, sorting, and counting the front pages with the same cutting shape can make it easier to calculate the accurate number of patients along with triage results.

FIGURE 1

Triage Tags. A: Typical triage tag with colored tabs. B: Novel triage tag with colored edges.

(A)

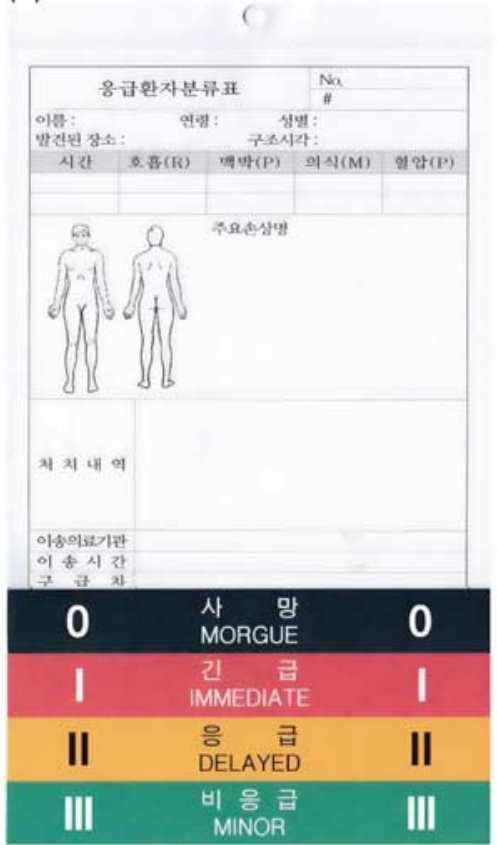

(B)

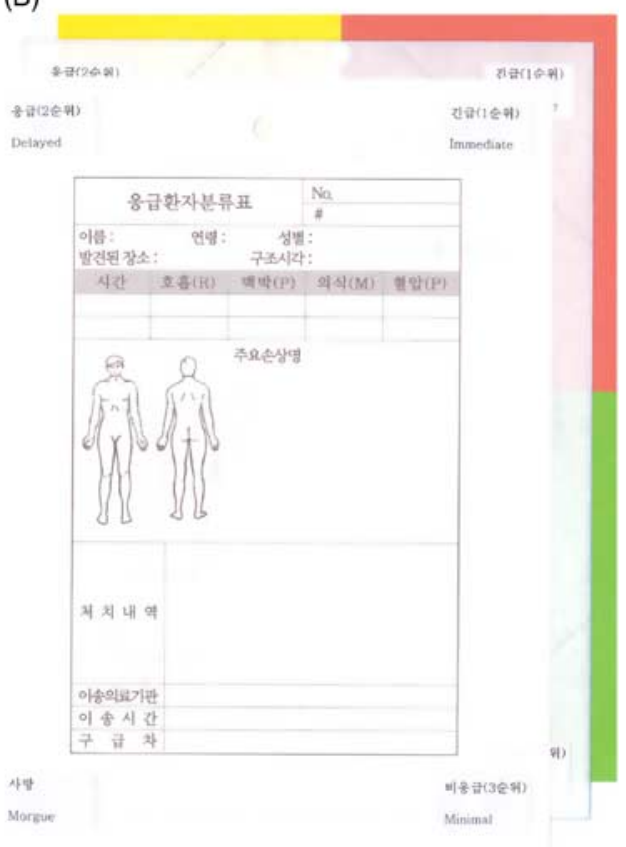




\section{FIGURE 2}

\section{Change in Triage Result.}
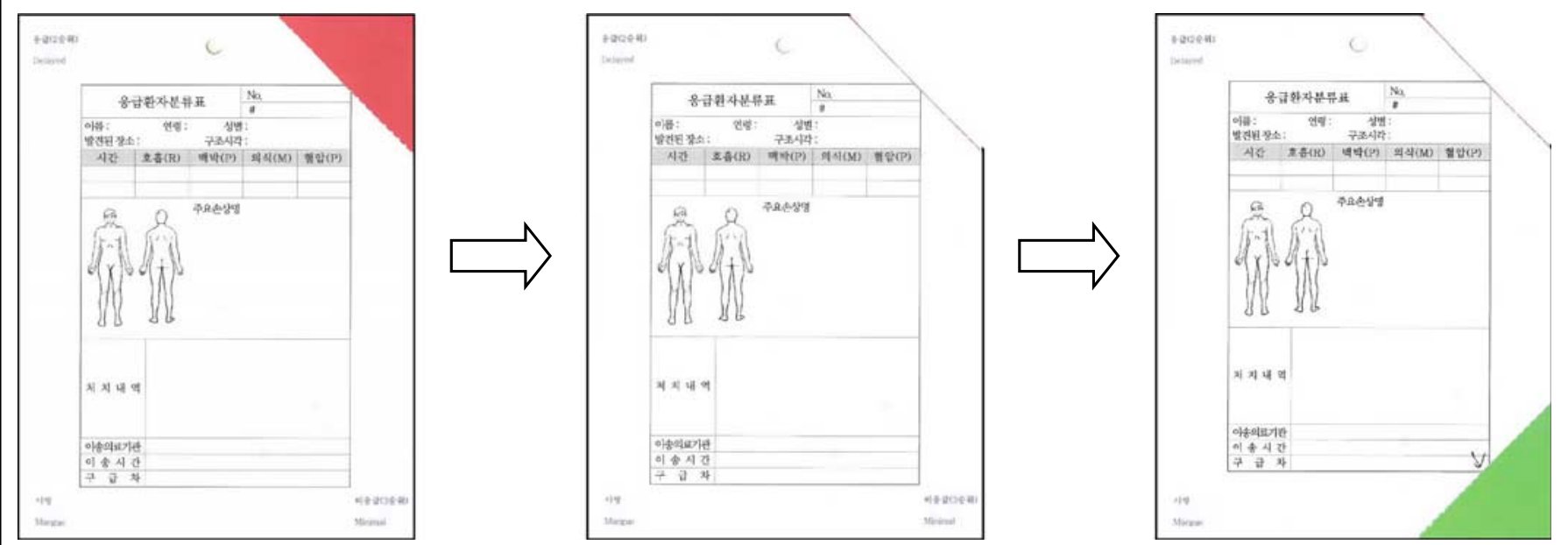

Paper triage tags can be considered old-fashioned in a certain way, especially when compared with wireless electronic devices. However, we believe that paper tags are still the first choice in disaster drill or education, with the advantage of a low initial cost. We hope that improvement in the design of paper triage tags will contribute to improving the operational capacity of students or trainees.

\section{About the Authors}

Department of Emergency Medicine, Myongii Hospital, Gyeonggi-do, Republic of Korea (Mr Kang and Dr Cha).
Correspondence and reprint requests to Dr Myeong-il Cha, Department of Emergency Medicine, Myeongji Hospital, Hwasu-ro 14beongil 55, Deokyang-gu, Goyang-si, Gyeonggi-do, Republic of Korea (e-mail: jennifer76cha@gmail.com).

Published online: June 28, 2016.

\section{REFERENCES}

1. Schultz CH, Koenig KL, Noji EK. A medical disaster response to reduce immediate mortality after an earthquake. $N$ Engl J Med. 1996;334(7): $438-444$

2. Garner A, Lee A, Harrison $\mathrm{K}$, et al. Comparative analysis of multiplecasualty incident triage algorithms. Ann Emerg Med. 2001;38(5):541-548.

doi: $10.1017 / \mathrm{dmp} .2016 .182$

\section{Caring for Cancer Patients After the Italian Earthquakes: A Proposal From the Field}

Lucilla Verna, MD'; Giampiero Porzio, MD’; Luca Napoleoni, MD; Giovanna Micolucci, MD; Rosa Rita Silva, MD; Raffaele Giusti, MD

T he recent earthquake that shook Central Italy confirmed once again the country's vulnerability. These events have serious consequences on the lives of cancer patients and on the organization of health care assistance. After the earthquake in Central Italy, as well as after the ones in L'Aquila and Emilia Romagna, nearby hospitals were declared unfit. Thus, patients were deprived of their reference health center. In addition, patients were 